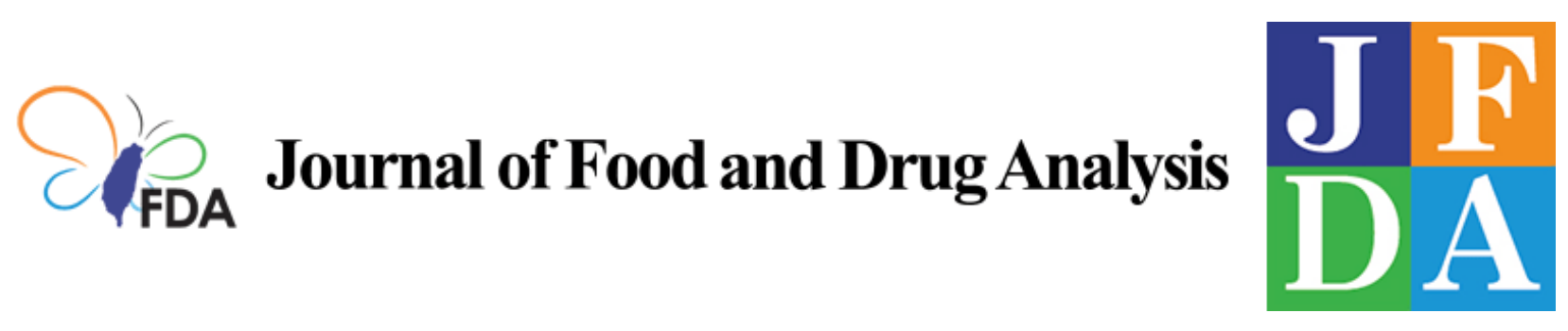

Volume 29 | Issue 2

Article 12

2021

\title{
Adverse effects on birth weight of parental illegal drug use during pregnancy and within two years before pregnancy
}

Follow this and additional works at: https://www.jfda-online.com/journal

Part of the Food Science Commons, Medicinal Chemistry and Pharmaceutics Commons, Pharmacology Commons, and the Toxicology Commons

(c) (i) (9)

This work is licensed under a Creative Commons Attribution-Noncommercial-No Derivative Works 4.0 License.

\section{Recommended Citation}

Lin, Ching-Heng; Lin, Wei-Szu; Wang, I-An; Hsu, Jui; Wu, Shiow-Ing; and Chen, Chuan-Yu (2021) "Adverse effects on birth weight of parental illegal drug use during pregnancy and within two years before pregnancy," Journal of Food and Drug Analysis: Vol. 29 : Iss. 2 , Article 12.

Available at: https://doi.org/10.38212/2224-6614.3355

This Original Article is brought to you for free and open access by Journal of Food and Drug Analysis. It has been accepted for inclusion in Journal of Food and Drug Analysis by an authorized editor of Journal of Food and Drug Analysis. 


\title{
Adverse effects on birth weight of parental illegal drug use during pregnancy and within two years before pregnancy
}

\author{
Ching-Heng Lin ${ }^{a, b, c, d, e}$, Wei-Szu Lin ${ }^{a}$, I-An Wang ${ }^{f}$, Jui Hsu ${ }^{\text {, }}$, \\ Shiow-Ing $W u^{h, i, *}$, Chuan-Yu Chen ${ }^{f, i}$
}

a Department of Medical Research, Taichung Veterans General Hospital, Taichung, Taiwan

${ }^{b}$ Department of Health Care Management, National Taipei University of Nursing and Health Sciences, Taipei, Taiwan

${ }^{c}$ Department of Public Health, College of Medicine, Fu Jen Catholic University, New Taipei City, Taiwan

d Department of Industrial Engineering and Enterprise Information, Tunghai University, Taichung, Taiwan

e Institute of Public Health and Community Medicine Research Center, National Yang Ming Chiao Tung University, Taipei, Taiwan

${ }^{\mathrm{f}}$ Center of Neuropsychiatric Research, National Health Research Institutes, Zhunan, Taiwan

${ }^{g}$ Division of Research and Analysis, Taiwan Food and Drug Administration, Taipei, Taiwan

${ }^{\text {h }}$ Institute of Population Health Sciences, National Health Research Institutes, Zhunan, Taiwan

${ }^{\mathrm{i}}$ Institute of Public Health, National Yang Ming Chiao Tung University, Taipei, Taiwan

\begin{abstract}
This study investigates possible links between maternal illegal drug use during pregnancy and up to two years before pregnancy with birth weight (BW), and explores the potential role of paternal illegal drug use on low birth weight. A population-based retrospective cohort study was conducted that linked four national databases in Taiwan. A total of 1,698 subjects with a criminal record of schedule I or II illegal drug use within two years before pregnancy were enrolled as the drug-exposed group, and 16,980 matched subjects were enrolled as the unexposed group. Multivariate analysis of BW found a decrease of $108.63 \mathrm{~g}(95 \% \mathrm{CI}:-172.29,-44.96), 79.67 \mathrm{~g}$ (95\% CI: - 116.91, -42.43), and $69.78 \mathrm{~g}$ (95\% CI: -106.71, -32.84) in newborns whose mothers used illegal drugs only during pregnancy (period I), only within one year before pregnancy (period II), and only within the second year before pregnancy (period III), respectively. Paternal use of illegal drugs before maternal pregnancy was significantly associated with low birth weight. The paternal effect on low birth weight was opposite the maternal effect. The adverse effect of illegal drug use on birth weight existed even if the mother did not use drugs during pregnancy but had ever used drugs during the two years before pregnancy. Paternal factors' contribution to low birth weight persisted, and the decrement of BW was even greater than the maternal effect within one or two years before pregnancy. Maternal and paternal illegal drug use may have a lasting effect on their offspring's birth weight.
\end{abstract}

Keywords: Birth weight, Drug criminal record, Duration of drug use, Maternal illegal drug use, Paternal illegal drug use

\section{Introduction}

$\mathrm{D}$ rug abuse has become a critical public health issue in many parts of the world, and a growing number of women use illegal drugs even during pregnancy. According to a national survey in the United States in 2012, 5.9\% of pregnant women used illicit drugs [1]. Prenatal illegal drug use can cause deleterious consequences in terms of pregnancy outcomes, including preterm labor, small-for-gestational age neonates, and low birth weight (LBW) [2-6]. As LBW accounts for most neonatal mortality and morbidity [7], researchers are becoming increasingly interested in the association between drug use and LBW, especially the timing of drug use [8,9], the paternal effect on LBW [10], and an adequate indicator to measure the exposure to illegal drug use [11].

Most studies to date have established the effects of time periods of illegal drug use through recorded

Received 8 December 2020; revised 29 April 2021; accepted 3 May 2021.

Available online 15 June 2021.

* Corresponding author at: Associate Investigator and Secretary General, Institute of Population Health Sciences, National Health Research Institutes, 35 Keyan Road, Zhunan, Miaoli County 35053, Taiwan. Fax: +886 37581891.

E-mail addresses: shiow@nhri.edu.tw, Shiowster@gmail.com (S.-I. Wu). 
data for short time periods, such as early pregnancy [12], six months before pregnancy [13], and three months before pregnancy [14]. Until now, to the best of our knowledge, no study has investigated the association of illegal drug use with LBW so far in advance of pregnancy as two years.

To determine the timing of illegal drug use, selfreporting, maternal or infant hair samples, and infant meconium have been used to clarify the association of illegal drug use with LBW, but there are some disadvantages to these measures [11,13,15-18]. To avoid our study being affected by these disadvantages, it used drug-related criminal records (DCRs) held by police departments as an indicator to determine whether women used illegal drugs or not.

Most studies aimed at the association between illegal drug use and birth outcomes recruited health-seeking samples and therefore are susceptible to selection bias, information bias, and disparities in health care, especially in vulnerable populations $[19,20]$. Pregnant women with illegal drug history often experience more severe social and structural barriers in seeking medical services due to social stigma, low social support, and disadvantaged socioeconomic condition [21,22]. Therefore, it's critical to tackle the reproductive outcome for this hidden population.

The majority of prior research has emphasized the impact of maternal characteristics on birth weight (BW). Many experts believe that maternal factors are more significant than paternal factors $[10,23,24]$; however, the effects of paternal drug use on BW remain controversial [25]. Therefore, it would be useful to understand the adverse effects of paternal drug use on BW.

The current study took these methodological limitations into account, and is one of the first to focus on the relationship between illegal drug use within one or two years before pregnancy and LBW in a large population-based cohort. We analyzed the nationwide Integrated Illegal Drug Database (IIDD), which included DCRs of schedule I and schedule II drugs from 2004 to 2017 in Taiwan. The aims of this study were to determine (1) the association between maternal illegal drug use and LBW, (2) whether the impact of illegal drug use on BW exists even long before pregnancy (up to two years), and (3) the contribution of paternal factors to LBW.

\section{Methods}

\subsection{Data sources}

In this study, four national databases, all of which are under the supervision of the Ministry of Health and Welfare, Taiwan, were linked. Those databases were as follows: (1) the 2004-2014 Taiwan Maternal and Child Health database, in which parent and child IDs are linked together; (2) the National Health Insurance Research Database (NHIRD), which is derived from the National Health Insurance Administration and contains $99 \%$ of the total population's medical care claims data since 1995 [26]; (3) the Birth Notification System (BNS) from 2004 to 2014, under which it is mandatory to report to the government newborns weighing more than $500 \mathrm{~g}$ or with a gestational age greater than 20 weeks [27]; and (4) the IIDD from the Health and Welfare Data Science Center, which consists of 20 illegal-drugrelated databases from different governmental agencies. The IIDD provided information on national drug scheduling and types of DCR (e.g., drug consumption, possession, manufacturing, trafficking, and distribution) from 2001 to 2017. All four databases are derived from administrative databases of Taiwan's government; the first two have been especially useful resources for population health sciences studies $[28,29]$.

This study was approved by the Institutional Review Board of the National Health Research Institutes, Taiwan (IRB number: EC 1070601-E). All personal data obtained were anonymized before analysis, and informed consent was thus waived.

\subsection{Study population}

In this retrospective cohort study, 1,272,723 pregnant women undergoing their first childbirth were selected in the first step to link the Taiwan Maternal and Child Health dataset with the NHIRD, and work was then carried out to link this dataset with the BNS from 2004 to 2014 . A total of $81,114(6.4 \%)$ of the $1,272,723$ subjects of pregnant women were excluded: those under 12 years old $(n=2)$, those who had multiple births $(n=22,653)$, and those missing a paternal identification number ( $n=58,459)$. The remaining 1,191,609 subjects were linked with the IIDD to determine whether the pregnant women had any DCR. In total, exactly 7,500 subjects were confirmed as having used drugs; the remaining 1,184,109 subjects had no DCR. Among the 7,500 subjects, a total of 1,698 had used a schedule I or schedule II illegal drug at least once during pregnancy or within two years before pregnancy; and 16,980 subjects were randomly selected from the non-illegal drug users to match illegal drug users (1:10) according to maternal age and year of childbirth (Fig. 1). 
2004-2014 Pregnant women $(n=1,272,723)$

linked data from Maternal and Child Health database, NHIRD, and BNS

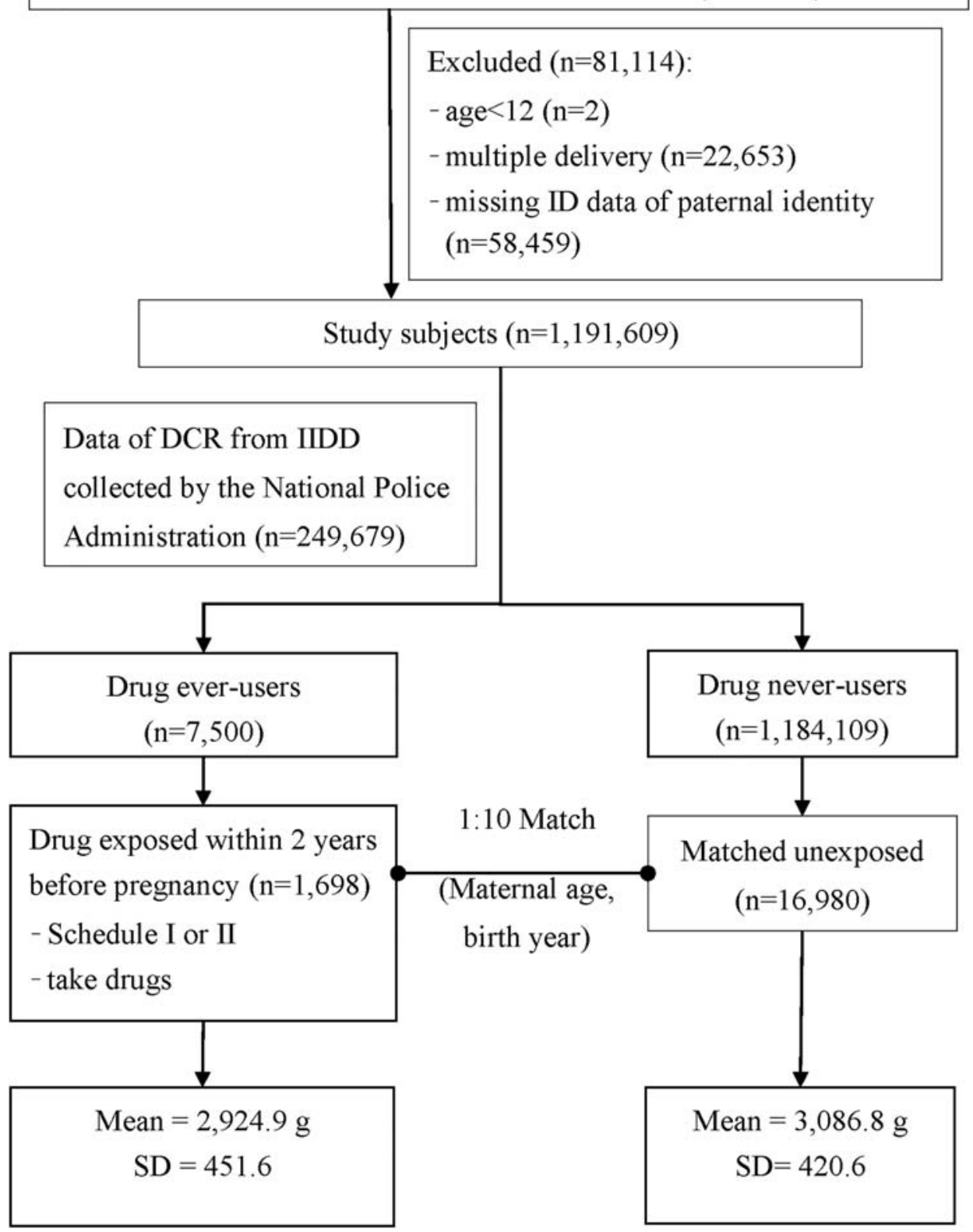

Fig. 1. Flow diagram of the study subjects.

\subsection{Measures}

\subsubsection{Exposure information}

Drug exposure was defined as having at least one DCR of schedule I or schedule II drug use during pregnancy or within two years before pregnancy. Those with DCRs of only drug possession, manufacturing, trafficking, or distribution were excluded from the analysis. The drug users must have tested positive during urine drug screening and then recorded as having a DCR by a police department. In addition, to explore the relationship between maternal ever use of illegal drugs and BW, the time of drug exposure was categorized into three periods. Period I was defined as having at least one DCR during pregnancy but without any record within two years before pregnancy. Period II was defined as at least one DCR within one year before pregnancy but without any record during pregnancy or within the second year before pregnancy. 
Period III was defined as at least one DCR use within the second year before pregnancy but without any record during pregnancy or within one year before pregnancy. Other combinations of DCR and period before or during pregnancy are possible; however, this study examines only periods I, II, and III to maintain clear-cut durations for comparison.

\subsubsection{Outcome information}

BW was retrieved from birth certificates in the BNS, for which weight was measured using a digital scale at birth and recorded in grams [27].

\subsubsection{Confounding variable information}

Information regarding income, urbanization level of residence (urban, suburban, rural), maternal comorbidities (diabetes mellitus, hypertension, hyperlipidemia, chronic obstructive pulmonary disease (COPD) [30-32], and pregnancy-related complications (gestational hypertension, preeclampsia, gestational diabetes mellitus) [33-35] were retrieved from the NHIRD. Maternal comorbidities were defined as applying to those who had inpatient or outpatient care with the diagnosis of diabetes mellitus, hypertension, hyperlipidemia or COPD during the two years before pregnancy. Pregnancy-related complications were defined as those of subjects who had inpatient or outpatient care with a diagnosis of gestational hypertension, pre-eclampsia, or gestational diabetes mellitus during pregnancy. Income was categorized into four levels using the payroll bracket table published by the Ministry of Health and Welfare's National Health Insurance Administration, and recorded in Taiwan dollars (TWD) [36]. Information regarding gestational age ( $\geq 37$ weeks, $<37$ weeks) [3] and mode of delivery (vaginal, cesarean) were retrieved from the BNS. Paternal drug use was defined as at least one DCR of schedule I or schedule II drug use during his wife's pregnancy or within two years before that time.

\subsection{Statistical analysis}

Data are presented as means \pm standard deviations (SD) for continuous variables and as numbers (percentages) for categorical variables. The independent $t$-test for continuous variables and Pearson's $\chi^{2}$ test for categorical variables were used for analysis. Multivariate linear regression models were used to determine the adverse effects of maternal illegal drug use on the risk of LBW, as shown by the beta coefficient $(\beta)$ with a $95 \%$ confidence interval (CI). Finally, in order to assess the robustness of the results, we repeated analyses of factors associated with BW according to the time period of drug exposure. All data were analyzed using SAS statistical software version 9.4 (SAS Institute, Cary, NC, USA). A $p$ value $<0.05$ was considered to indicate statistical significance.

\section{Results}

Table 1 shows the basic characteristics of the study population. A higher percentage of drug-exposed subjects had a significantly lower socioeconomic status $(66.5 \%)(p<0.001)$ and lived in regions of lower urbanization $(51.5 \%)(p<0.001)$. In the drugexposed group, $33.9 \%(p<0.001)$ of all parents were drug users, and $60.1 \%(p<0.001)$ of the subjects had a vaginal delivery. The prevalences of maternal comorbidities and pregnancy-related complications among the drug-exposed group were comparable to the matched unexposed group, except the prevalences of hyperlipidemia $(0.6 \%$ vs. $1.2 \%, p=0.033)$ and gestational diabetes mellitus $(0.6 \%$ vs. $2.3 \%$, $p<0.001$ ) were lower in the drug-exposed group than in the matched unexposed group. In addition, the drug-exposed subjects were more likely than the matched unexposed group to have a baby that was small for the gestational age $(12.7 \%$ vs. $6.5 \%$, $p<0.001$ ). Of the 1,698 drug-exposed subjects, the rates of drug use were $16.4 \%, 33.0 \%$, and $30.9 \%$ for periods I, II, and III, respectively.

Multivariable analysis showed that maternal drug-exposed subjects $(-100.25 \mathrm{~g}, 95 \% \mathrm{CI}:-123.77$, -76.74), those whose husbands had ever used illegal drugs ( $-64.33 \mathrm{~g}$, 95\% CI: $-99.78,-28.87)$, those with hypertension $(-87.37 \mathrm{~g}$, 95\% CI: $-158.38,-16.36)$, those with pre-eclampsia $(-269.40 \mathrm{~g}, 95 \%$ CI: $-321.93,-216.86)$, and those whose neonate had a gestational age less than 37 weeks $(-658.89 \mathrm{~g}, 95 \%$ CI: $-680.68,-637.10$ ) had a lower mean neonate BW as compared with their counterparts (Table 2). In addition, the neonatal BWs of mothers aged 25-29, $30-34$, and $\geq 35$ years were, respectively, 20.41 ( $95 \%$ CI: $6.80,34.02), 42.28$ (95\% CI: $26.40,58.17)$, and $54.68 \mathrm{~g}$ (95\% CI: $33.07,76.30)$, greater than those for infants of mothers aged $<25$, and BW declined by 4.87 g (95\% CI: $-6.77,-2.97)$ per year. However, pregnant women with a cesarean delivery, diabetes, or gestational diabetes were associated with a higher neonatal BW (Table 2).

To explore whether illegal drug use long before pregnancy had an impact on neonatal BW, multivariable regression models of $B W$ by period of illegal drug use were performed. The results (Table 3) showed a gradient of decreasing BW with duration of maternal illegal drug use. Subjects exposed to illegal drugs had a $108.63 \mathrm{~g}$ decrease (95\% CI: 
Table 1. Characteristics of study subjects by drug exposure.

\begin{tabular}{|c|c|c|c|}
\hline \multirow[t]{2}{*}{ Characteristic } & \multirow{2}{*}{$\begin{array}{l}\frac{\text { Drug-exposed }}{(\mathrm{n}=1698)} \\
\mathrm{n}(\%)\end{array}$} & \multirow{2}{*}{$\begin{array}{l}\text { Matched unexposed } \\
(\mathrm{n}=16980) \\
\mathrm{n}(\%)\end{array}$} & \multirow[t]{2}{*}{$p$-value } \\
\hline & & & \\
\hline Maternal age (years) & & & 1.000 \\
\hline$<25$ & $599(35.3)$ & $5990(35.3)$ & \\
\hline $25-29$ & $579(34.1)$ & $5790(34.1)$ & \\
\hline $30-34$ & $368(21.7)$ & $3680(21.7)$ & \\
\hline$\geq 35$ & $152(9)$ & $1520(9)$ & \\
\hline Year of childbirth & & & 1.000 \\
\hline 2004 & $66(3.9)$ & $660(3.9)$ & \\
\hline 2005 & $257(15.1)$ & $2570(15.1)$ & \\
\hline 2006 & $254(15)$ & $2540(15)$ & \\
\hline 2007 & $171(10.1)$ & $1710(10.1)$ & \\
\hline 2008 & $210(12.4)$ & $2100(12.4)$ & \\
\hline 2009 & $153(9)$ & $1530(9)$ & \\
\hline 2010 & $116(6.8)$ & $1160(6.8)$ & \\
\hline 2011 & $126(7.4)$ & $1260(7.4)$ & \\
\hline 2012 & $118(6.9)$ & $1180(6.9)$ & \\
\hline 2013 & $112(6.6)$ & $1120(6.6)$ & \\
\hline 2014 & $115(6.8)$ & $1150(6.8)$ & \\
\hline Paternal drug use & & & $<0.001$ \\
\hline No & $1123(66.1)$ & $16906(99.6)$ & \\
\hline Yes & $575(33.9)$ & $74(0.4)$ & \\
\hline Income (TWD) & & & $<0.001$ \\
\hline$\leq 15840$ & $1129(66.5)$ & $3053(18)$ & \\
\hline $15841-28800$ & $497(29.3)$ & $9218(54.3)$ & \\
\hline $28801-45800$ & $59(3.5)$ & $3511(20.7)$ & \\
\hline$>45800$ & $13(0.8)$ & $1198(7.1)$ & \\
\hline Urbanization of residence $^{a}$ & & & $<0.001$ \\
\hline Urban & $823(48.5)$ & $9916(58.4)$ & \\
\hline Suburban & $298(17.6)$ & $2346(13.8)$ & \\
\hline Rural & $576(33.9)$ & $4711(27.8)$ & \\
\hline Mode of delivery & & & $<0.001$ \\
\hline Vaginal delivery & $1020(60.1)$ & $11666(68.7)$ & \\
\hline Cesarean section & $678(39.9)$ & $5314(31.3)$ & \\
\hline \multicolumn{4}{|l|}{ Maternal comorbidities } \\
\hline Diabetes mellitus & $8(0.5)$ & $81(0.5)$ & 0.973 \\
\hline Hypertension & $13(0.8)$ & $109(0.6)$ & 0.546 \\
\hline Hyperlipidemia & $10(0.6)$ & $196(1.2)$ & 0.033 \\
\hline COPD & $44(2.6)$ & $475(2.8)$ & 0.622 \\
\hline \multicolumn{4}{|l|}{ Pregnancy-related complications } \\
\hline Gestational hypertension & $10(0.6)$ & $100(0.6)$ & 1.000 \\
\hline Pre-eclampsia & $22(1.3)$ & $197(1.2)$ & 0.621 \\
\hline Gestational diabetes mellitus & $11(0.6)$ & $399(2.3)$ & $<0.001$ \\
\hline Gestational age & & & $<0.001$ \\
\hline$\geq 37$ weeks & $1482(87.3)$ & $15875(93.5)$ & \\
\hline$<37$ weeks & $216(12.7)$ & $1105(6.5)$ & \\
\hline \multicolumn{4}{|l|}{ Exposure period } \\
\hline Period I & $278(16.4)$ & & \\
\hline Period II & $561(33.0)$ & & \\
\hline Period III & $524(30.9)$ & & \\
\hline
\end{tabular}

${ }^{\text {a }}$ Missing:8.

$-172.29,-44.96)$ in $\mathrm{BW}$ in period $\mathrm{I}$, a $79.67 \mathrm{~g}$ decrease $(95 \% \mathrm{CI} ;-116.91,-42.43)$ in period II, and a $69.78 \mathrm{~g}$ decrease (95\% CI: -106.71, -32.84) in period III. Moreover, paternal use of illegal drugs was significantly associated with LBW in both period II $(-115.05 \mathrm{~g}, 95 \% \mathrm{CI}:-223.89,-6.21)$ and period III $(-128.33 \mathrm{~g}$, 95\% CI: $-254.05,-2.60)$. The trend of BW decrease affected by paternal factor was opposite that of the maternal effect (Table 3 ).

\section{Discussion}

Using a population-based retrospective dataset formed by linkage of 4 useful government registries 
Table 2. Multivariable linear regression of birth weight $(n=18,678)$.

\begin{tabular}{|c|c|c|c|c|}
\hline \multirow{2}{*}{$\begin{array}{l}\text { Variables } \\
\text { Mother used drugs }\end{array}$} & \multirow{2}{*}{$\frac{\text { Beta }(\beta) \text { coefficient }}{-100.25}$} & \multicolumn{2}{|c|}{$95 \%$ Confidence limits } & \multirow{2}{*}{$\frac{p \text { value }}{<0.001}$} \\
\hline & & -123.77 & -76.74 & \\
\hline Father used drugs & -64.33 & -99.78 & -28.87 & $<0.001$ \\
\hline \multicolumn{5}{|l|}{ Maternal age (years) } \\
\hline$<25$ & reference & & & \\
\hline $25-29$ & 20.41 & 6.80 & 34.02 & 0.003 \\
\hline $30-34$ & 42.28 & 26.40 & 58.17 & $<0.001$ \\
\hline$\geq 35$ & 54.68 & 33.07 & 76.30 & $<0.001$ \\
\hline Year of childbirth & -4.87 & -6.77 & -2.97 & $<0.001$ \\
\hline \multicolumn{5}{|l|}{ Income (TWD) } \\
\hline$\leq 15840$ & reference & & & \\
\hline $15841-28800$ & 1.07 & -13.72 & 15.86 & 0.887 \\
\hline $28801-45800$ & -0.97 & -19.58 & 17.64 & 0.919 \\
\hline$>45800$ & 15.73 & -10.40 & 41.86 & 0.238 \\
\hline \multicolumn{5}{|l|}{ Urbanization of residence } \\
\hline Urban & reference & & & \\
\hline Suburban & 1.74 & -14.79 & 18.28 & 0.836 \\
\hline Rural & -6.11 & -18.97 & 6.76 & 0.352 \\
\hline \multicolumn{5}{|l|}{ Gestational age } \\
\hline$\geq 37$ weeks & reference & & & \\
\hline$<37$ weeks & -658.89 & -680.68 & -637.10 & $<0.001$ \\
\hline \multicolumn{5}{|l|}{ Mode of delivery } \\
\hline Vaginal delivery & reference & & & \\
\hline Cesarean section & 50.48 & 38.42 & 62.54 & $<0.001$ \\
\hline \multicolumn{5}{|l|}{ Maternal comorbidities } \\
\hline Diabetes mellitus & 148.10 & 65.18 & 231.03 & 0.001 \\
\hline Hypertension & -87.37 & -158.38 & -16.36 & 0.016 \\
\hline Hyperlipidemia & 30.52 & -24.40 & 85.45 & 0.276 \\
\hline COPD & -13.95 & -47.59 & 19.70 & 0.417 \\
\hline \multicolumn{5}{|l|}{ Pregnancy-related complications } \\
\hline Gestational hypertension & -46.40 & -118.94 & 26.15 & 0.210 \\
\hline Pre-eclampsia & -269.40 & -321.93 & -216.86 & $<0.001$ \\
\hline Gestational diabetes mellitus & 94.23 & 55.92 & 132.54 & $<0.001$ \\
\hline
\end{tabular}

and administrative databases, we found that BW decreased by an average of $108 \mathrm{~g}$ if the mother was exposed to illegal drugs during pregnancy, and there was a decreasing trend of BW with the period of maternal illegal drug use. These results are consistent with those of most other studies, showing that the risk of LBW was significantly higher in women who used illegal drugs during pregnancy $[2,3,37,38]$.

Despite interest in the association between BW and duration of drug use, no one, to the best of our knowledge, has traced back participants' drug-use history so long before pregnancy (up to two years). The most striking point of our study was that we adopted DCR to establish that BW can still be affected even when the maternal illegal drug exposure occurred only within one year before pregnancy, and without any DCR during pregnancy (period II). The effects persisted even when drug users were exposed to drugs within two years before pregnancy and without any DCR thereafter (period III). In our study, we should sound a note of caution with regard to those subjects without DCR, because some probably still used drugs but did not happen to be arrested for this. Because the drug-exposure effect is likely an underestimation, the statistically significant association between drug exposure and LBW means the true decrease in BW would be greater than the value presented in Table 3.

Using DCR as the indicator to determine drugexposure history has some advantages. One is that the validity of DCR is very high, especially in Taiwan, because the drug users not only were caught red-handed but also tested positive in a urine screening. Another advantage is that DCR could compensate for the limitations that arise from self-reporting, hair sampling, and infant meconium testing. Self-reporting has a very low sensitivity [3941] and is not an adequate measure of drug use in a pregnant population [13]. Maternal and infant hair samples have some weaknesses, including incomplete removal by washing and drug concentration changed by cosmetics $[17,18,42]$. In comparison with the abovementioned methods, DCR appears to be a relatively reliable indicator to measure drug-exposure history. According to the 2014 National Survey of Substance Use in Taiwan, lifetime prevalences were $0.23 \%$ for heroin users and $0.6 \%$ for 


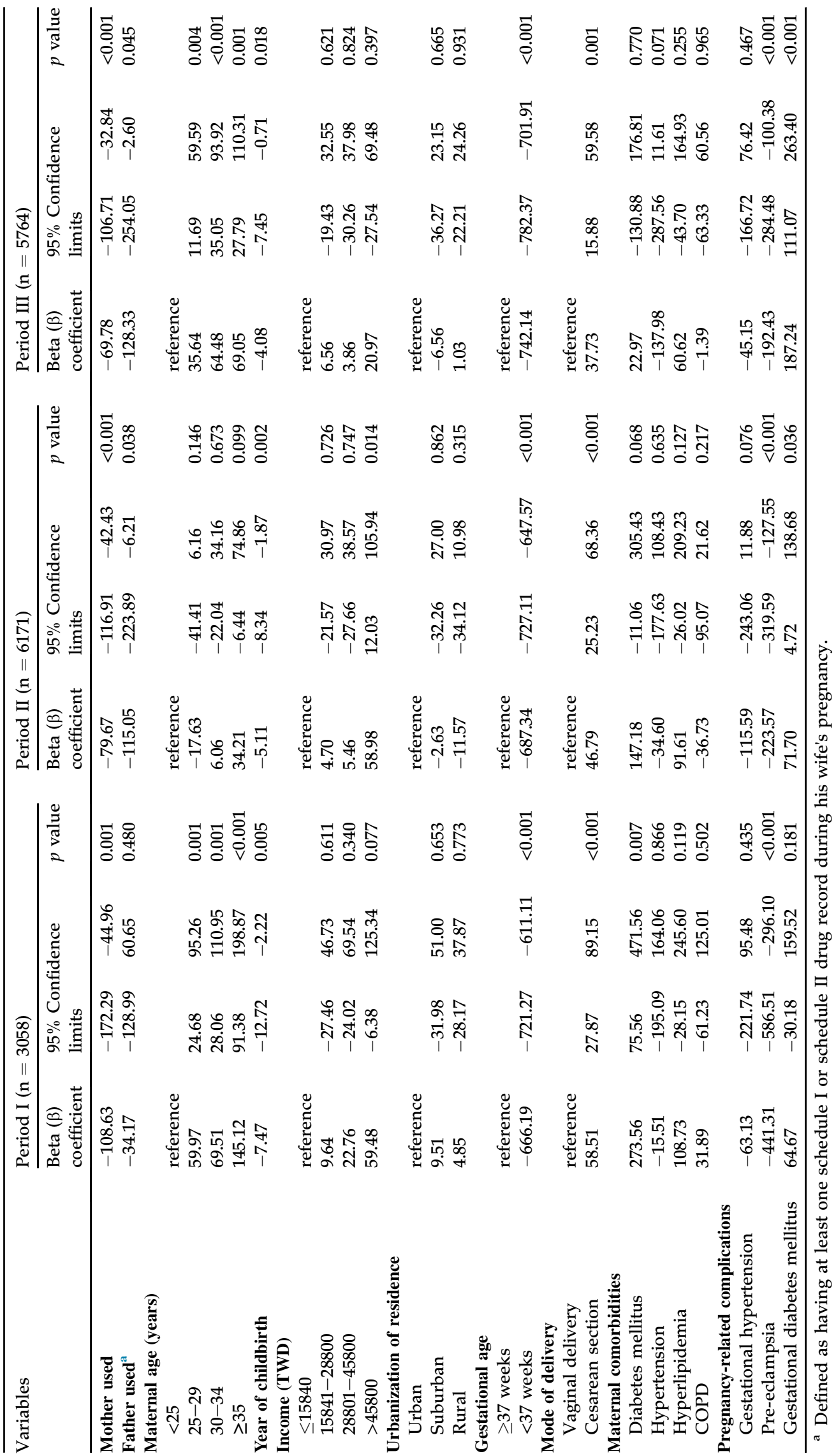


methamphetamine users [43]; these results are very low compared with Western countries [44,45]. Our findings would seem to imply that DCR provides an important opportunity to examine the association between maternal and paternal illegal drug use on BW in a non-Western country. However, using DCR to determine drug-exposure history still has a disadvantage: the probability of being arrested by police is not random, especially for illegal drug users. Drug users are caught more often at druginvolved scenes/settings (e.g., karaoke bars, internet cafes, or nightclubs) than at home [46].

The causal relationship between maternal illegal drug use and LBW is very complex and affected by multiple risk factors, including socio-demographic, medical, and behavioral ones [47-49]. Almost all researchers have tried to control as many as risk factors as possible, but no study could control for a comprehensive set of associated factors, especially for information related to illegal drugs [49]. Since our study used information from DCRs, variables such as lifestyle or risk behaviors (e.g., smoking) cannot be asserted and adjusted. Therefore, the association might be unfavorable lifestyle factors [50,51] or inadequate access to healthcare services among drug users [50,52-55]. Our study also found that the rate of pregnant women in the drug-exposed group who did not receive any prenatal visits was $16.5 \%$, compared to just $9 \%$ in the matched unexposed group ( $p<0.05$, data not shown).

The impact of maternal drug use on BW is better established by previous studies than paternal factors. BW correlations were found to be higher for mother-child than for father-child [23]. Some studies did not find that paternal cannabis use [12] or paternal involvement [25] were associated with fetal growth. Although maternal drug use during pregnancy has a larger effect on BW than paternal factors, our study showed that after adjustment for confounding factors, paternal drug exposure was still significantly associated with $\mathrm{BW}$ and a greater BW loss than maternal effect in periods II and III. Our research could not identify the reasons for the higher contribution of paternal factors than maternal factors to LBW in periods II and III; we believe important factors related to LBW might be due to paternal low socioeconomic status [56,57], paternal low educational attainment [10,57-61], paternal lifestyle factors [62], intimate partner violence [63-69], and the relationship between fathers and mothers [24].

Our research may have three limitations. First, our subjects were limited to married couples, excluding unmarried domestic partners. Because one of our study's aims was to investigate the parental factors related to LBW, we had to exclude $4.6 \%$ of subjects missing a paternal identification number. Second, lifestyle behaviors were not available in the four national databases that we used. Lifestyle behaviors (e.g., cigarette smoking) are believed to be an important risk factor for LBW. Some studies found that the risk of LBW was significantly higher for pregnant women who smoked cigarettes than for those who used drugs [12,58,70-73]. Other studies found the effect of smoking on BW was less than that of illegal drug use [74-77]. The smoking rate of women in Taiwan is $2.4 \%$ [78], which is much lower than that in the United States $(15.9 \%)$ and Britain $(19.5 \%)$ [79]. Our study might slightly overestimate the impact of illegal drug use on BW by not taking into account tobacco smoking; nevertheless, the estimated association did not have appreciable differences once we used maternal COPD as a proxy for tobacco use in multivariate analyses.

The third limitation is, because of pervasive multidrug use and potential interactions between different illegal drugs, it is difficult to differentiate the consequences of each individual illegal drug on BW [9]. This is the reason our study did not analyze individual drug effects on BW but used schedule I and schedule II drug offenders as a group to explain the association between illegal drug use and LBW.

\section{Conclusion}

Our work has led us to conclude that maternal illegal drug exposure was associated with increased risk of lower birth weight, and that there is a gradient of decreasing $\mathrm{BW}$ corresponding to the period of maternal illegal drug exposure. The adverse effect on BW continues to exist even if the mother did not use illegal drugs during pregnancy but had ever used drugs during the one or two years before pregnancy. The contribution of paternal factors to LBW persists, and the decrement of BW is even greater than the maternal effect within one or two years before pregnancy. We provide further evidence that maternal and paternal drug use may have a lasting effect on their offspring's birth weight.

Our research highly suggests a window of intervention opportunity to provide readily accessible integrated addiction treatment and reproductive health services for drug-involved women when they encounter the law enforcement and correctional systems.

\section{Acknowledgements}

This research was funded by a grant from the National Health Research Institutes, Taiwan (PH107-PP-33). We acknowledge those governmental 
agencies - including the Ministry of Health and Welfare, the Ministry of Justice, the Ministry of the Interior, the National Police Agency, the Criminal Investigation Bureau, the Ministry of Education, the Ministry of Labor, and the Judicial Yuan - that built the nationwide Integrated Illegal Drug Database (IIDD), as well as the Ministry of Health and Welfare for establishing the Collaboration Center of Health Information Application. We would like to thank Lee She Fen and Wen-Ing Tsay of the Taiwan Food and Drug Administration for assistance with administrative processes to facilitate this collaborative intragovernmental effort. We gratefully acknowledge the help provided by Dr. Wei J. Chen, Dr. I-Shou Chang, and Dr. Kung-Yee Liang of the National Health Research Institutes, Zhunan, Taiwan, through constructive comments that greatly improved the manuscript.

\section{References}

[1] United States Department of Health and Human Services. Substance Abuse and Mental Health Services Administration. Center for Behavioral Health Statistics and Quality. National Survey on Drug Use and Health. Inter-university Consortium for Political and Social Research (ICPSR). Ann Arbor, MI: Inter-university Consortium for Political and Social Research [distributor]. Available at 2015. p. 11-23 http://dx.doi.org/10.3886/ICPSR35509.v3. [Accessed 7 December 2020].

[2] Fuddy LJ, Prince CB, Tang MC. Perinatal substance use among high risk women in Hawaii: Patterns and impact on pregnancy outcomes. Asian Am Pac Isl J Health 2003;10: 50-7.

[3] Hon KL, Chan MH, Ng MH, Ho CC, Tsang KY, Tam WH, et al. Urine comprehensive drug screen, low birth weight and withdrawal symptoms in a neonatal unit: a case control study. Curr Clin Pharmacol 2016;11:274-81.

[4] Hulse GK, Milne E, English DR, Holman CD. The relationship between maternal use of heroin and methadone and infant birth weight. Addiction 1997;92:1571-9.

[5] Miller C, Grynspan D, Gaudet L, Ferretti E, Lawrence S, Moretti F, et al. Maternal and neonatal characteristics of a Canadian urban cohort receiving treatment for opioid use disorder during pregnancy. J Dev Orig Health Dis 2019;10: 132-7.

[6] Oliveira TA, Bersusa AA, Santos TF, Aquino MM, Mariani Neto C. Perinatal outcomes in pregnant women users of illegal drugs. Rev Bras Ginecol Obstet 2016;38:183-8.

[7] Murphy CC, Schei B, Myhr TL, Du Mont, Abuse J. A risk factor for low birth weight? A systematic review and metaanalysis. CMAJ 2001;164:1567-72.

[8] Coles CD, Platzman KA, Smith I, James ME, Falek A. Effects of cocaine and alcohol use in pregnancy on neonatal growth and neurobehavioral status. Neurotoxicol Teratol 1992;14: 23-33.

[9] Lamy S, Laqueille $X$, Thibaut F. Consequences of tobacco, cocaine and cannabis consumption during pregnancy on the pregnancy itself, on the newborn and on child development: A review. Encephale 2015;41(S1):S13-20.

[10] Shah PS. Knowledge Synthesis Group on determinants of preterm/low birthweight $b$. Paternal factors and low birthweight, preterm, and small for gestational age births: a systematic review. Am J Obstet Gynecol 2010;202:103-23.

[11] Kuhn L, Kline J, Ng S, Levin B, Susser M. Cocaine use during pregnancy and intrauterine growth retardation: new insights based on maternal hair tests. Am J Epidemiol 2002;152: $112-9$.

[12] El Marroun $\mathrm{H}$, Tiemeier $\mathrm{H}$, Steegers EA, Jaddoe VW, Hofman A, Verhulst FC, et al. Intrauterine cannabis exposure affects fetal growth trajectories: the Generation R Study. J Am Acad Child Adolesc Psychiatry 2009;48:1173-81.

[13] Fergusson DM, Horwood LJ, Northstone K, ALSPAC Sudy Team. Avon longitudinal study of pregnancy and childhood. maternal use of cannabis and pregnancy outcome. BJOG 2002;109:21-7.

[14] Shankaran S, Das A, Bauer CR, Bada HS, Lester B, Wright LL, et al. Association between patterns of maternal substance use and infant birth weight, length, and head circumference. Pediatrics 2004;114:e226-34.

[15] Eyler FD, Behnke M, Conlon M, Woods NS, Wobie K. Birth outcome from a prospective, matched study of prenatal crack/cocaine use: I. Interactive and dose effects on health and growth. Pediatrics 1998;101:229-37.

[16] Frank DA, Augustyn M, Zuckerman BS. Neonatal neurobehavioral and neuroanatomic correlates of prenatal cocaine exposure. Problems of dose and confounding. Ann N Y Acad Sci 1998;846:40-50.

[17] Reid RW, O'Connor FL, Crayton JW. The in vitro differential binding of benzoylecgonine to pigmented human hair samples. J Toxicol Clin Toxicol 1994;32:405-10.

[18] Welch MJ, Sniegoski LT, Allgood CC, Habram M. Hair analysis for drugs of abuse: Evaluation of analytical methods, environmental issues, and development of reference materials. J Anal Toxicol 1993;17:389-98.

[19] Agency for Healthcare Reseaech and Quality. Race, Ethnicity, and Language Data: Standardization for Health Care Quality Improvement, Introduction. Rockville, MD. available at, https://www.ahrq.gov/research/findings/finalreports/iomracereport/index.html. [Accessed 20 April 2018].

[20] Westhoff CL. Epidemiologic studies: Pitfalls in interpretation. Dialogues Contracept 1995;4:5-68.

[21] Neale J, Tompkins C, Sheard L. Barriers to accessing generic health and social care services: a qualitative study of injecting drug users. Health Soc Care Community 2008;16:147-54.

[22] Matsuzaki M, Vu QM, Gwadz M, Delaney JAC, Kuo I, Trejo MEP, et al. Perceived access and barriers to care among illicit drug users and hazardous drinkers: findings from the Seek, Test, Treat, and Retain data harmonization initiative (STTR). BMC Public Health 2018;18:366.

[23] Magnus P, Gjessing HK, Skrondal A, Skjaerven R. Paternal contribution to birth weight. J Epidemiol Community Health 2001;55:873-7.

[24] Misra DP, Caldwell C, Young Jr AA, Abelson S. Do fathers matter? Paternal contributions to birth outcomes and racial disparities. Am J Obstet Gynecol 2010;202:99-100.

[25] Straughen JK, Caldwell CH, Young Jr AA, Misra DP. Partner support in a cohort of AfricanAmerican families and its influence on pregnancy outcomes and prenatal health behaviors. BMC Pregnancy Childbirth 2013;13:187.

[26] Fang SY, Huang N, Tsay JH, Chang SH, Chen CY. Excess mortality in children born to opioid-addicted parents: A national register study in Taiwan. Drug Alcohol Depend 2018;183:118-26.

[27] Wu TP, Liang FW, Huang YL, Chen LH, Lu TH. Maternal mortality in Taiwan: A nationwide data linkage study. PLoS One 2015;10:e0132547.

[28] Hsing AW, Ioannidis JP. Nationwide population science: Lessons from the Taiwan national health insurance research database. JAMA Intern Med 2015;175:1527-9.

[29] Chou HH, Chiou MJ, Liang FW, Chen LH, Lu TH, Li CY. Association of maternal chronic disease with risk of congenital heart disease in offspring. CMAJ 2016;188: E438-46.

[30] Knop MR, Geng TT, Gorny AW, Ding R, Li C, Ley SH, et al. Birth weight and risk of type 2 diabetes mellitus, cardiovascular disease, and hypertension in adults: A meta-analysis of 7646267 participants from 135 studies. J Am Heart Assoc 2018;7:e008870. 
[31] Li N, Li Z, Ye R, Zhang L, Li H, Zhu Y, et al. Preconception blood pressure and risk of low birth weight and small for gestational age: A large cohort study in China. Hypertension 2016;68:873-9.

[32] Maymunah AO, Kehinde O, Abidoye G, Oluwatosin A. Hypercholesterolaemia in pregnancy as a predictor of adverse pregnancy outcome. Afr Health Sci 2014;14:967-73.

[33] Gillman MW, Rifas-Shiman S, Berkey CS, Field AE, Colditz GA. Maternal gestational diabetes, birth weight, and adolescent obesity. Pediatrics 2003;111:e221-6.

[34] Rahman LA, Hairi NN, Salleh N. Association between pregnancy induced hypertension and low birth weight; a population based case-control study. Asia Pac J Public Health 2008;20:152-8.

[35] Szymonowicz W, Yu VY. Severe pre-eclampsia and infants of very low birth weight. Arch Dis Child 1987;62:712-6.

[36] National Health Insurance Administration MOHW. Taiwan. Payroll bracket table. available at. 2019. https://www.nhi.gov. tw/english/Content_List.aspx? $\mathrm{n}=70 \mathrm{~F} 57 \mathrm{BED} 87 \mathrm{C} 9 \mathrm{~F} 67 \mathrm{~A} \& \mathrm{topn}=\mathrm{E} 84 \mathrm{~A} 5021 \mathrm{~B} 8 \mathrm{~B} 64995$. [Accessed 7 December 2020].

[37] Homsup P, Phaloprakarn C, Tangjitgamol S, Manusirivithaya S. Maternal characteristics and pregnancy outcomes among illicit drug-using women in an urban setting. Taiwan J Obstet Gynecol 2008;57:83-8.

[38] Noonan K, Reichman NE, Corman H, Dave D. Prenatal drug use and the production of infant health. Health Econ 2007;16: 361-84.

[39] Garg M, Garrison L, Leeman L, Hamidovic A, Borrego M, Rayburn WF, et al. Validity of self-reported drug use information among pregnant women. Matern Child Health J 2016; 20:41-7.

[40] Grant T, Brown Z, Callahan C, Barr H, Streissguth AP. Cocaine exposure during pregnancy: improving assessment with radioimmunoassay of maternal hair. Obstet Gynecol 1994;83:524-31.

[41] Kline J, Ng SK, Schittini M, Levin B, Susser M. Cocaine use during pregnancy: sensitive detection by hair assay. Am J Public Health 1997;87:352-8.

[42] Jurado C, Kintz P, Menendez M, Repetto M. Influence of the cosmetic treatment of hair on drug testing. Int J Legal Med 1997;110:159-63.

[43] Chen WJ, Wu SC, Tsay WI, Chen YT, Hsiao PC, Yu YH, et al. Differences in prevalence, socio-behavioral correlates, and psychosocial distress between club drug and hard drug use in Taiwan: Results from the 2014 National Survey of Substance Use. Int J Drug Policy 2017;48:99-107.

[44] Center for Disease Control and Prevention, National Center for Health Statistics: Health, United States. 2018 - Data Finder. available at. 2018. https://www.cdc.gov/nchs/hus/ contents2018.htm. [Accessed 7 December 2020].

[45] NIH National Institute of Drug Abuse. National Survey of Drug Use and Health. available at. 2013. https://www.drugabuse. gov/national-survey-drug-use-health. [Accessed 7 December 2020].

[46] Taiwan Food and Drug Administration. Drug abuse surveillance and reporting system. Available at. 2018. https:// www.fda.gov.tw/ENG/siteListContent.aspx? $\operatorname{sid}=10217 \& i d=27710$. [Accessed 7 December 2020].

[47] Bendersky M, Alessandri S, Gilbert P, Lewis M. Characteristics of pregnant substance abusers in two cities in the northeast. Am J Drug Alcohol Abuse 1996;22:349-62.

[48] Lindenberg CS, Reiskin HK, Gendrop SC. The social stress model of substance abuse among childbearingage women: A review of the literature. J Drug Educ 1994;24:253-68.

[49] Schempf AH, Strobino DM. Illicit drug use and adverse birth outcomes: is it drugs or context? J Urban Health 2008;85: 858-73.

[50] Chomitz VR, Cheung LW, Lieberman E. The role of lifestyle in preventing low birth weight. Future Child 1995;5:121-38.

[51] Mahmoodi Z, Karimlou M, Sajjadi H, Dejman M, Vameghi M, Dolatian M. A communicative model of mothers' lifestyles during pregnancy with low birth weight based on social determinants of health: A path analysis. Oman Med J 2017;32:306-14.

[52] Chen CY, Wang IA, Fang SY, Huang N, Tsay JH, Chang SH. Inadequate prenatal care utilization among women with and without methadone-treated opioid use disorders in Taiwan. Int J Drug Policy 2019;67:1-8.

[53] Hughes D, Simpson L. The role of social change in preventing low birth weight. Future Child 1995;5:87-102.

[54] Knowlton AR, Hoover DR, Chung SE, Celentano DD, Vlahov D, Latkin CA. Access to medical care and service utilization among injection drug users with HIV/AIDS. Drug Alcohol Depend 2001;64:55-62.

[55] Pinzon-Rondon AM, Gutierrez-Pinzon V, MadrinanNavia H, Amin J, Aguilera-Otalvaro P, Hoyos-Martinez A. Low birth weight and prenatal care in Colombia: a crosssectional study. BMC Pregnancy Childbirth 2015;15:118.

[56] Leung JY, Leung GM, Schooling CM. Socioeconomic disparities in preterm birth and birth weight in a non-Western developed setting: evidence from Hong Kong's 'Children of 1997' birth cohort. J Epidemiol Community Health 2016;70: 1074-81.

[57] Meng Y, Groth SW. Fathers Count: The Impact of Paternal Risk Factors on Birth Outcomes. Matern Child Health J 2018; 22:401-8.

[58] Bailey BA, McCook JG, Hodge A, McGrady L. Infant birth outcomes among substance using women: Why quitting smoking during pregnancy is just as important as quitting illicit drug use. Matern Child Health J 2012;16:414-22.

[59] Nicolaidis C, Ko CW, Saha S, Koepsell TD. Racial discrepancies in the association between paternal vs. maternal educational level and risk of low birthweight in Washington State. BMC Pregnancy Childbirth 2004;4:10.

[60] Parker JD, Schoendorf KC, Kiely JL. Associations between measures of socioeconomic status and low birth weight, small for gestational age, and premature delivery in the United States. Ann Epidemiol 1994;4:271-8.

[61] Shapiro GD, Bushnik T, Sheppard AJ, Kramer MS, Kaufman JS, Yang S. Paternal education and adverse birth outcomes in Canada. J Epidemiol Community Health 2017; 71:67-72.

[62] Alemu A, Abageda M, Assefa B, Melaku G. Low birth weight: prevalence and associated factors among newborns at hospitals in Kambata-Tembaro zone, southern Ethiopia 2018. Pan Afr Med J 2019;34:68.

[63] Alhusen JL, Ray E, Sharps P, Bullock L. Intimate partner violence during pregnancy: maternal and neonatal outcomes. J Womens Health (Larchmt) 2015;24:100-6.

[64] Berhanie E, Gebregziabher D, Berihu H, Gerezgiher A, Kidane G. Intimate partner violence during pregnancy and adverse birth outcomes: a case-control study. Reprod Health 2019;16:22

[65] Chaves K, Eastwood J, Ogbo FA, Hendry A, Jalaludin B, Khanlari S, et al. Intimate partner violence identified through routine antenatal screening and maternal and perinatal health outcomes. BMC Pregnancy Childbirth 2019;19:357.

[66] Chen PH, Rovi S, Vega ML, Barrett T, Pan KY, Johnson MS. Birth outcomes in relation to intimate partner violence. J Natl Med Assoc 2017;109:238-45.

[67] Ferdos J, Rahman MM. Maternal experience of intimate partner violence and low birth weight of children: A hospital-based study in Bangladesh. PLoS One 2017;12:e0187138.

[68] Laelago T, Belachew T, Tamrat M. Effect of intimate partner violence on birth outcomes. Afr Health Sci 2017;17:681-9.

[69] Sigalla GN, Mushi D, Meyrowitsch DW, Manongi R, Rogathi JJ, Gammeltoft T, Rasch V. Intimate partner violence during pregnancy and its association with preterm birth and low birth weight in Tanzania: A prospective cohort study. PLoS One 2017;12:e0172540.

[70] Conner SN, Bedell V, Lipsey K, Macones GA, Cahill AG, Tuuli MG. Maternal marijuana use and adverse neonatal outcomes: A systematic review and meta-analysis. Obstet Gynecol 2016;128:713-23. 
[71] Janisse JJ, Bailey BA, Ager J, Sokol RJ. Alcohol, tobacco, cocaine, and marijuana use: relative contributions to preterm delivery and fetal growth restriction. Subst Abus 2014;35: 60-7.

[72] Shiono PH, Klebanoff MA, Nugent RP, Cotch MF, Wilkins DG, Rollins DE, et al. The impact of cocaine and marijuana use on low birth weight and preterm birth: a multicenter study. Am J Obstet Gynecol 1995;172:19-27.

[73] Visscher WA, Feder M, Burns AM, Brady TM, Bray RM. The impact of smoking and other substance use by urban women on the birthweight of their infants. Subst Use Misuse 2003;38: 1063-93.

[74] Zhao L, McCauley K, Sheeran L. The interaction of pregnancy, substance use and mental illness on birthing outcomes in Australia. Midwifery 2017;54:81-8.

[75] English DR, Hulse GK, Milne E, Holman CD, Bower CI. Maternal cannabis use and birth weight: A meta-analysis. Addiction 1997;92:1553-60.
[76] Fan C, Huang T, Cui F, Gao M, Song L, Wang S. Paternal factors to the offspring birth weight: The 829 birth cohort study. Int J Clin Exp Med 2015;8:11370-8.

[77] Gray TR, Eiden RD, Leonard KE, Connors GJ, Shisler S, Huestis MA. Identifying prenatal cannabis exposure and effects of concurrent tobacco exposure on neonatal growth. Clin Chem 2010;56:1442-50.

[78] Health Promotion Administration, MOHW. Adult Smoking Behavior Surveillance System. Available at. 2018. https:// www.hpa.gov.tw/Pages/Detail.aspx? nodeid $=1718 \&$ pid $=9913$. [Accessed 7 December 2020].

[79] WHO. Global Health Observatory data repository: Prevalence- adult age-standardized data by country. Available at. $2018 . \quad$ https://www.hpa.gov.tw/Pages/Detail.aspx? nodeid $=1718 \&$ pid=9913. [Accessed 7 December 2020]. 